\title{
A review on environmental forensics and environmental law in the Malaysian perspective
}

\begin{abstract}
Environmental law which is pertinent for the purpose of environmental protection and pollution control requires the assistance of forensic investigation and analytical sciences to investigate what is in the environment, where it has come from, and using that data to detect, prevent or prosecute environmental crime. In Malaysia and elsewhere, law enforcers are relying heavily on the scientific discipline of environmental forensics in order to prove, to the satisfaction of a court of law, who is responsible for instances of pollution. Specifically for Malaysia, environmental liabilities are generally the remit of the Department of Environment through enforcement of the Environmental Quality Act 1974. This Act is the main law enacted to help attain the objective of environmental policy which is to balance economic and environmental needs for the purpose of sustainable development. This Act is also the key piece legislation that has formed the basis of many prosecutions, and it contained various provisions that concerned directly or indirectly with environmental forensics. The objectives of this paper are to examine the Act, and to identify its relevance towards the application of environmental forensics within the legal process for the purpose of achieving the overall objectives of environmental protection and sustainable development. This research is very important because at the moment, there is a very limited number of other known researches in Malaysia that examine environmental forensics from the legal perspective. Thus this research should help policy makers, law enforcers, judiciary, scientists and other relevant stakeholders understand and expand their knowledge of environmental forensics in the context of law.
\end{abstract}

Keyword: Environmental law; Environmental liability; Environmental forensics; Judicial approach; Environmental protection 